\title{
WHEN OPINION LEADERS TWEET: FRAMING ANALYSIS OF KUWAITI PARLIAMENT MEMBERS' TWEETS
}

\author{
Fatima Al SALEM \\ Indiana University, School of journalism, USA \\ alsalem_fatima@yahoo.com
}

\begin{abstract}
This research investigated Kuwaiti parliament members' leadership behavior on Twitter by applying Bolman and Deal's (1984) leadership theory of framing. The study classified parliament members according to their political party affiliation-Islamists, independents, liberals, and populists party- and investigated the prevalence of four leadership frames through a content analysis of eight parliament members' messages on Twitter over a period of six months from June 15, 2011 to November 15, 2011. Results showed that, overall, the structural frame was the most commonly used frame among parliament members, followed by the political, symbolic, and human resource frame respectively. The use of frames depended on both the political group and the topic of issues. The Islamist group, liberal and populist party more often used the structural frame in their Twitter messages whereas the independent group more often used the political frame.
\end{abstract}

Keywords: Opinion leaders, Twitter, New media, Framing

\section{INTRODUCTION}

In many ways social media provide an interesting space for opinion expression and political discourse, and many people speculate its possible democratic implications for people living in less democratic countries. Twitter as a form of social media extends the opportunity that other social media offer due to its immediacy, great social interaction, and informal discussion. Moreover, Twitter is ranked as the fastest-growing site in the member community category in the U.S., while in Kuwait Twitter users' penetration is ranked sixth among the Middle East and North African Countries and third among the Gulf countries (Nielson, 2011; Arab Social Media Report, 2011). An increasing number of Kuwaitis are using Twitter because its free, easy to use, and provides a space for opinion expression and research found that 24 percent of social media users in Kuwait use it for political discussion (Alfadhly, 2011). In addition to general users, opinion leaders in Kuwait such as parliament members (law makers), cabinet ministers, political and social activists are using Twitter as it represents a channel where they can disseminate ideas, build on their social capital, interact collaboratively, and build on their public image. The study is noteworthy in many ways. First, it fills a gap in research as there is dearth of research relating to framing social media users' leadership behaviors. Second, the study contributes to framing theory and the leadership theory of framing by Bolman and Deal (1984) in several ways.

The study demonstrates yet another area within mass communication scholarship in which the framing theory may be usefully applied to social networking sites. For leadership theory of framing by Bolman and Deal (1984), this study marks one of the initial examination of the theory in the political communication arena. In addition, this study extends the theory by introducing a non-organizational landscape and builds on recent effort by scholars. Lastly, Kuwait's media system is interesting in many ways, although the country has a strict press and publication law that limits the criticism of the Amir and Islam, there is an unfiltered Internet access. The 
unfiltered access to the Internet and social media sites explains the high penetration rates of Kuwaiti users of social media sites as there is a space for freedom of opinion expression online. The freedom online that Kuwaitis have makes the Internet a political forum and opinion leaders such as parliament member use it to reach out to their followers and gain more exposure. Therefore, It is significant to examine how parliament members use social media through investigating their leadership behavior expressed through their Twitter messages which can explain their motivations.

\section{LITERATURE REVIEW}

\section{Social Media Use in Kuwait}

In Kuwait, according to the constitution that was agreed upon between Kuwaitis and the ruling family in 1964, the legislature can exert its power over the executive branch. Although the Amir maintains the final word on most government policies, the National Assembly plays a real role in decision-making, with powers to initiate legislation, question cabinet ministers, and express lack of confidence in individual ministers (U.S. Department of State, 2010). Recent Internet World Stats (2011) rank Kuwait as sixth in terms of Internet usage and population percentages in the Middle East with a $42.4 \%$ penetration. In terms of social media use, World Stats figures show that there are 822,640 Facebook users in Kuwait as of 2010 (WorldStat, 2011). In terms of Twitter users, statistics show that there are 113,428 active users of Twitter in Kuwait as of March 2010, a $3.24 \%$ penetration (Arab Social Media Report, 2011). The Arab Social Media Report shows that Kuwait ranks sixth in terms of the number of active Twitter users in the Arab countries after Turkey, Qatar, Egypt, UAE and Saudi Arabia (Arab Social Media Report, 2011).

Politically speaking, Kuwait is one of the three countries that represent 17 percent of the Middle East identified as having a partly free press along with Morocco and Lebanon (Freedom House, 2010). Although the partly free press in Kuwait means Kuwaitis can criticize the government and express their political opinions through newspaper articles, blogs and television, still Kuwait has strict press laws limiting criticism of the Amir and Islam. Moreover, In 2008, Kuwait's Public Prosecutors office issued a bill to punish Internet offenders in the country. The penalties for breaking the law could involve up to one year in prison, seven years if the insulted party is a minor, and monetary fines. The law is set to criminalize immoral conduct, encouraging any antigovernment statements, divulging state secrets or offending Islam online (WAN/IFEX, 2008). Despite the press and publication law, Kuwait has unfiltered access to the Internet (Hofheinz, 2005) compared to other countries in the region which explains the high penetration rate of Internet users in general and social media in specific. According to Wheeler (2006) there are three reasons for the active Kuwaiti Internet atmosphere: (1) culturally, Kuwaitis like to show-off their social status by being the first to own the latest trend, and this attitude has made Kuwaitis anxious to get online; (2) economically, Kuwaitis have one of the highest per capita incomes, meaning they can afford to buy computers and Internet subscriptions, and (3) finally, the government supports a techno-savvy culture by allowing the sale of and access to high-tech devices. There are several reasons for the high numbers of social media users in Kuwait as Haqaq (2011) explains that Facebook, Twitter and other channels help spread the message more widely. Moreover, social media usage in Kuwait is not limited to social interaction between people, entertainment or marketing but acquires a far greater role (Haqaq, 2011). Social media is used as a political tool and Kuwaiti citizens' use has been described as the most intriguing in the Gulf region (AlQassemi, 2011). Recent Pew center research show that 73 percent of Americans surf the Internet for political reasons, and the situation is pretty similar in Kuwait. Although there is lack of research on social media usage in Kuwait, recent events showed that Twitter was a 
mobilization tool. Twitter was used in Kuwait to mobalize and organize protests against the Prime Minister Sheikh Nasser AlMohammed Al Sabah that started on March 2011 and the increased political discussions on Twitter prove that Kuwaitis use social networking sites for political reasons (GetConnect, 2011). In addition, Twitter is increasingly being used as the most popular channel for political discussion among Kuwaiti citizens because of its wide audience reach, speed, and the short messages feature (Haqaq, 2011). Another factore that can't be neglected is Kuwaitis ability to own smart phones due to their middle to high incomes that makes social networks accessible from their phones. Haqaq (2011) adds that the high number of people using smart phones in Kuwait helped in encouraging the use of social media such as Twitter and Facebook because people connect to these tools straight from their phones without the need to be sitting behind a laptop anymore. In her study about the Internet in Kuwait, Wheeler (2003) argued the Internet trasnformed the communicative practices in the Kuwaiti society. As the traditional social forum for political discussion and gatherings has always been the diwaniya (Male social clubs), where Kuwaiti men would gather to discuss issues, latest events, and debate about politics. (Haqaq, 2011). But the introduction of the Intenet has changed the diwaniya custom and many young people argue that they enjoy to surf the Net over traditional social gatherings. Social media tools became the new public forums for the new Kuwaiti generation as they use it for political discussion (Ismail \& Mazeedi, 1998 \& Haqaq 2011). Politicians, ministers and members of parliament MPs (law makers) in Kuwaiti have followed the trend and are using Twitter to discuss politics and interact with the public. AlQaseemi (2011) notes that social media in Kuwait is more like an extension of the Kuwaiti parliament, where parliament members discuss policies and interact with their followers from the general public. Wheeler (2001) believes that some Kuwaitis are taking advantage of the Internet as a vehicle for challenging Kuwait's conservative society's view on proper public interaction. The Internet supports the untraditional chains of authority, which provides an attractive experiment in which to interact with unfamiliar or endangerd forms of social interaction (Wheeler, 2001) Moreover, Haqaq (2011) argues that parliament members in Kuwait joined Twitter after they have noticed the shift in the political forums and the great participation. Social Media like Twitter is a great opportunity for parliament members and political figures to read conversation between the public, interact with general people, and participate in the people-government dialogue (Haqaq, 2011). AlMutairi (2011) asserts that Kuwaiti MPs' usage of Twitter is a phenomena and they use it to interact with their followers and gain public support. In addition, MPs in Kuwait use Twitter messages to support their positions on policies and use it as an alternative source to mainstream media to reach out to their supporters especially when rumors spread about them or when they need to defend certain positions (AlMutairi, 2011).

Members of parliament and politicians have different political agendas and might use the Internet and social media for different purposes. Ku et al., (2003) argue that politicians have begun to use the Internet to mobilize supporters and convery their messages through online strategies. When studying MPs in Kuwait, it is unfair to refer to them as one homogeneous group, as they belong to different political groups and have different political ideologies that range from Islamists to liberals. Therefore, this study analyzes MPs' Twitter messages as part of their political groups to examine whether differences in leadership exist among political groups.

\section{Kuwait Political Groups}

Official political parties are illegal in Kuwait, they have not been legalized since the independence in 1961. Yet, the Kuwaiti 1962 constitution does not prohibit political parties in any of its articles. Nevertheless, there are several political groups that act as de facto political parties ( Encyclopedia of the Nations, 2011). The rational for prohibitting the existence of 
political parties in Kuwait is that political parties may be a divisive factor in a tribally-based society with many social divisions i.e. Sunni vs. Shi'a. tribal vs. town (The Estimate, 1999). Political groups in Kuwait have their own codes, headquarters, funding from their supporters, and have their set of objectives, yet they do not have formal memberships and therefore it is difficult to assess exactly how much strength they enjoy in a given parliament (The Estimate, 1999). Nevertheless, Alfuzai (2007) asserts that all political groups in Kuwait have their own spokespersons or representatives in the parliament i.e. MPs that follow their ideology.

In elections, several major political grouping function as parties to support their candidates. AlFuzai (2007) argues that although political parties have no clearance by the Kuwaiti law, parties act like "big shots." Therefore, political groups have the power of de facto parties and there are several legislative voting blocs in the parliament (Ziegler, 2011). The main political groups are the Islamists, liberals, populist party, and independents. The Islamists include Sunni Islamists, Shia Islamists, Muslim Brotherhood, and Salafist group, while the liberals include the National Democratic Alliance, Democratic Forum (left) and independent members. The independents mostly include the pro-government MPs which include Shia, Sunni, and tribal members. Lastly the populists group are the government opponents (Herb, 2009).

Islamists: The Islamic group is the most influential bloc in the parliament with around 19 elected members in the 2009 national election (Herb, 2009). The Islamist group includes memebrs from Muslim brotherhood, Salfis, Shi'a Islamists, and Sunni Islamists. Their main demand that Sharia be the only source for all laws in Kuwait. One of the most important bills passed by the islamic group in the past years was the elimination of co-education in 1998 between females and males in university level. Islamists are concerned with social issues such as censorship, limiting women's freedom, and fighting homosexuality (Kareem, 2011).

Populist Party: The popular action bloc is headed by Ahmed Alsadoun. The party focues on populist issues such as housing, salary raises, and unemployment. The party emerged in the late nintees in Kuwait and has three representatives in the Kuwait National Assembly in the last elections of 2009. The main objectives of the populist party's are to defend the constitution of 1962, defend the public money and serve the public. Among the most prominent acheivements of the party were the residential care act, the law of state property, Warba Bank (Islamic Bank), and Kuwait's third telecommunication company. The populist partly is considered the leading governmnet opposition and its deputies.

Independents: The independent parliament members constitute of sunni, shia, and tribal members. They tend to support the ruling family and the governmet deputies in the parliament and have won 21 seats in the 2009 national elections.

Liberals: The liberal members of the parliamnet belong to The National Democratic Alliance, Democratic Forum, or independent liberal members. They are progressive and liberal. Their main goals are to acheive democracy and respect for human rights and build civil society. They are mainly concerned with economic policies, national reconstruction and the development and expansion of production and investment projects and to achieve social justice. In 2009 national elections, the liberals won 6 seats in the parliamnet.

In summary, it is inevitable that opinion leaders such as politicians, parliament members and activitsts need to be part of social media and interact with the public, and many of them already are but what is equally important is to study their behavior. There are several approaches to examine opinion leaders' social media use and framing their messages can be a significant way. Nevertheless, the analysis show that parliamnet members in Kuwait belong to diverse political parties and groups, therefore the study will focus on the differences of framing social media usage among MPs political groups. 


\section{Framin Theory}

Over the years scholars have developed a body of research on framing and framing effects (Sametko \&Valkenburg, 2000 \& Druckman, 2001). Despite the numerous amount of research that examines framing and its effects, there is no single definition of framing but many that have been developed include the same characteristics (Sametko \&Valkenburg, 2000). Neuman et al., (1992) defined framing as the conceptual tools individuals and media rely on to interpret and evaluate information (Sametko \&Valkenburg, 2000). Those frames help individuals locate, perceive and identify the information around them (Goffman, 1974). Sametko \&Valkenburg (2000) argue that there are two possible approaches to content analyze frames in the news: inductive and deductive. The inductive way often involves small samples as it analyzes news stories with loosely defined preconceptions of some frames and attempts to reveal an array of possible frames that may exist. On the other hand, the deductive approach involves predefining certain frames and verify the extent of their occurrence in the news. This approach makes it necessary to have a clear idea of the kind of frames that may appear to avoid over looking certain frames that have not been predefined (Sametko \&Valkenburg, 2000).

The literature has identified many frames that exist in the media which usually measures the existence of certain frames in the news such as conflict frame, economic consequences frame and morality frame (Valkenburg \& Sametko, 2000). This study does not attempt to analyze the news media per se but social media messages of parliament members to study their leadership behavior. Therefore, this study provides an extension of the research of Bolman and Deal's $(1984,1991)$ by investigating the occurence of the different frames of leadership in parliament members' Twitter messages. Leadership research started in the early twentieth century with research that focused on the personal characteristics of leaders. Research on personal characteristics of leaders initiated trait theory which suggests that leaders have specific traits that differentiat them form their followers (Mossers \& Walls, 2002). Stodgill's research on leaders' behaviors rather than their characteristics have shifted the emphasis of leadership reaserch. The behavior approach was concerend with leaders behavior that is capable of being changed (Mossers \& Walls, 2002). In the late 1970s, the transformational leadership approach was initiated that is based on personal values and beliefs. Furthermore, transformational leaders define the need for change, create a vision, inspire and unite their followers to follow that vision. Mossers \& Walls (2002) argue that Bolman and Deal's development of the leadership frames in the 1980s was the most useful typology to examine and study leadership.

Bolman and Deal's leadership frames notes that leaders view experiences according to different leadership styles and frames (Sasnett \& Ross, 2007). In addition, scholars argue that Bolman and Deal's theory (1984) is a synthesis of existing research on leadership which categorizes leadership into 'frames' that are considered to be windows on the world (Sasnett \& Ross, 2007 \& Mossers \& Walls, 2002). The theory consists of four frames: structural, human resource, political and symbolic. Each frame provides a specific version of leadership styles and techniques. Structural leaders define clear goals and assign specific roles while the human resource frame focuses on needs of people and value people's feelings and relationships. The political frame focuses on competition among different constitunecies for scarce resources. Lastly, the symbolic frame provide sense of mission and identity and leaders on that frame focus on enthusiasm, culture, and charisma (Bolman \& Deal, 1991).

Scholars such as Mossers \& Walls (2002) argue that research on framing leadership practices has been conducted to examine how leaders use leadership frames by focusing on whether they 
demonstrate behaviors described in each frame. The literature on Bolman and Deal's leadership frames afford us to apply a deductive approach to examine the prevalence of frames in the Kuwaiti parliament members' Twitter messages. Although there is a body of literature on Bolman and Deal's leadership frames, the frames have been mostly used to assess organizational leaders (Mossers \& Walls, 2002; Sasnett \& Ross, 2007; Bolman \& Deal, 1984, 1991, 1997). Therefore, this study will investigate the four leadership frames by Bolman and Deal (1984) with some modification in the operationalization definition of each frame for them to be more relevent to asses political leaders. Structural frame. This frame emphasizes on effeciency and effectiveness. Structural leaders define clear goals, assign specific roles for their followers and supporters. This frame of leadership tries to coordinate internal process with external environment and coordinate specific activities with policies and procedures (Sassnet \&Ross, 2007). Other research has also observed that critical analysis of issues and events was highly valued in the structural frame (Bolman \& Deal, 1991). Zolner (2010) found that in structural frames, leaders frame problems in a way that they orginate from inappropriate structures and can be resolved through reorganization and restructuring.

Human resource frame. The human resource frame focuses on needs of people. Leaders within this frame value feelings and relationships of people. This frame of leadership strives for a good relationship within the work environment (parliament). Sassnet \&Ross (2007) observe that human resource frame is based on meeting the needs of the people through empowerment. Moreover, human resource leaders attempt to be responsive to people's needs to gain loyalty. This frame emphasizes on support and empower people through participation( Bolman \& Deal, 1991). Political Frame. Political frame is built on negotiation. Political leaders advocate and build their power bases through networking. In this frame, it is evident that leaders recognize the diversity of individuals, interests and compete for scarce resources (Sassnet \&Ross, 2007). The political leader understands conflict and can deal with the different agendas interest groups may have. In addition, political frame usually consists of reasonable compromises for negotiaitions and conflict. Symbolic Frame. The symbolic frame emphasizes meaning, symbols and culture. Symbolic leaders value the subjective and achieve thier goals through interpretative rituals. These leaders rely on traditions and values. Zolner (2010) observed that the symbolic farme assumes that humans will create and use meaning to clarify confusion and predict mystery. In addition, leaders working in this frame instill enthusiasim and drama to their followers (Sassnet \&Ross,2007; Bolman \& Deal, 1991).

\section{PURPOSE OF THE STUDY}

The purpose of this study is to examine the utilization of leadership frames in Kuwaiti members of parliament's Twitter messages, and to examine differences between the various political groups (Islamists, populists party, liberals, and independents). With these goals in mind, the following research questions were devised:

RQ1: What is the most commonly used leadership frame (structural, symbolic, human resource, or political) by Kuwaiti parliament members?

RQ2: Does the use of structural, symbolic, human resources and political leadership frames vary by political group?

A second aim of this study is to compare the use of leadership frames in Kuwaiti parliament members' Twitter messages and different topics or issues that they commonly Tweet about (political issues, for example, or social), and to consider the implications of the type of messages they post. The third research question is: 
RQ3: Does the use of structural, symbolic, human resources, and political leadership frames by parliament members vary by topic?

\section{METHODS}

This study proceeded from a quantitative contetnt analysis of the leadership frames used in Kuwaiti MPs Twitter messages from June 15, 2011 to November 15, 2011 using a systematic random sampling method. This period was picked as it covers the period when most MPs joined Twitter and became active users. There are 26 parliament members on Twitter as of November $15,2011,52 \%$ of the total population of parliament members in Kuwait, yet some have established their accounts and never posted a single message. Therefore, it was important to identify active MPs first. There is no single definition of active Twitter user, according to Barracuda Labs, an active twitter user is someone who has at least 10 followers, follows at least 10 people and has tweeted 10 times(Leggatt, 2010). Moreover, Twitter's product lead manager asserts that his team identify active users when users follow 30 accounts and when one-third of the people they follow also follow them back (Carlson, 2011). On the other hand, according to Twitter CEO Dick Cotolo, an active user of Twitter is anyone who logs into Twitter at least once a month $(\mathrm{Ogg}, 2011)$. The multiple definitions of active users on Twitter, allow us to pick the best definition that fits our research agenda, therefore, Barracuda Labs' definition will be applied where users are considered active when they have 10 followers, follow 10 accounts and tweeted 10 times (Leggatt, 2010). This definition qualifies with the research purspose as it takes into consideration the message activity unlike other definitions that focus on the number of followers. After applying Barracuda Labs' definition of active users on Kuwaiti MPs, only 15 out of the 26 membrs were qualified as active users. Since the research focuses on members' political groups, the 15 members are not eqaully distributed between the political groups i.e. there are only two liberal members that fit into the criterea of active users while there are more Islamic memebrs. Therefore, the decision has been made to pick the top two members from the four political groups (populists's party, Islamists, liberals, and independents) who fit into the active user category and have the top activity (measured by number of messages). Members of parliament's political orientation was identified by Kuwait Politics Database (Herb, 2009). After the top two MPs of each political group (Islamists, populists's party, liberals, independents) has been identified from each political group based on their Twitter account activity and Barcuda Labs' definition of active users, a systematic random samplying of their messages has been applied from June 15, 2011 to November 15, 2011. The main purpose was to generate a systematic random sample of $25 \%$ of every parliament member total messages for the research period. The purpose of the study is to examine MPs' messages and leadership behavior, therefore only initial posts by MPs were included in the analysis. This means that any message that was sent as a reply to someone else's message was not included, in addition to forwarded messages (Retweets) that are not written by the MP were excluded as well. This was identified in advance as a basis for selecting the sampling population of messages because the research was concerned with initial messages and statements not discussions. A full 278 MPs Twitter messages met these criteria and were therefore used in the framing analysis. After retrieving MPs messages, a content analysis was applied to study the topics of their Tweets, examine the most prominant topic and the differences between members. Selected messages were coded for the main topics: politics, economics, social, religion, and international affairs. Messages were coded for their type (a) news release or a comment about the current issues and events (b) statement, thoughts or random ideas (c) quote by a different author (d) use of multimedia such as pictures of videos. Each of these types were coded (1) yes or (0) no.

\section{Framing Measure}


To measure the extent to which certain frames appear in messages, a series of 16 questions were developed to which the coder answered yes (1) or no (0). Each question was meant to measure one of the four frames: structural, human interest, political, symbolic. These were questions such as "Does the message contain any quotes from the Quraan?" (symbolic), "Does the message suggest that the leader is assigning any roles for his followers?" (structural), "Does the message message contain any conflict?" (political), and "Is there any use of supportive words by the message sender?" (human resources).

Intercoder Reliability

The intercoder reliability conducted on a subsample of $15 \%$ of the Twitter messages showed a 91\% reliability based on Holsti's (1969) formula.

\section{FINDINGS}

This study consisted of Twitter messages' content analysis of eight parliament members, two from each political group. A total of 278 Twitter messages were collected and analyzed to determine the most frequent leadership frame used. The sample constituted of: two Islamists parliament members' messages $37.4 \%$, two independent $7.9 \%$, two liberal members $29.9 \%$, and two members from the populist party $24.8 \%$ of the total population of analyzed Twitter messages(See Table 1 for more details). Findings show that $61.5 \%$ of Islamist members' messages were statements, $9.6 \%$ were quotes, while $16.3 \%$ of Islamist members' messages were in the form of press releases. Moreover, $15.4 \%$ of Islamists' messages included multimedia and graphics. On the other hand, $73.5 \%$ of liberal parliament members' messages were statements, $16.9 \%$ were press releases, and only $3.6 \%$ of their messages included multimedia. Independent parliament members' messages were mostly statements ( $81.8 \%$ ), with only $18.2 \%$ press releases and there found to be no use of multimedia in their messages. Similarly, there found to be no use of multimedia among populist party members, while $62.3 \%$ of their messages were statements, $30.4 \%$ found to be press releases.

\section{Use of Frames by Different Political Groups}

The first research question asked about the most commonly used leadership frame among the different parliament members in their Twitter messages. To investigate whether the use of frames varied, a simple frequency test of the 16 questions was conducted over the total population. The frequency test yielded many findings, and indicated that, overall, the structural leadership frame was the most frequently used frame across the sample $(\mathrm{n}=235)$. The second most common used frame by parliament members was the political frame $(n=168)$, followed by symbolic frame $(n=125)$, and human resource frame $(n=107)$ respectively. To answer the second research question which asked whether the use of leadership frames varied among (Islamists, independent, liberal and populist party) political groups, a frequency analysis of the prevalence of frames among each political group was conducted. Table 2 shows the most used leadership frame by the Islamist political parliament members was the structural frame $(\mathrm{n}=88)$, followed by the symbolic frame $(n=65)$, and the political frame came third $(n=60)$. On the other hand, the independent political group most used frame on Twitter was the political frame $(n=18)$, followed by the structural frame $(n=16)$ and the symbolic frame came on the third place. On contrast, the liberal political group and the populist party both employed the structural frame the most. The liberal group used the structural frame the most in their Twitter messages $(n=68)$, followed by the political frame $(n=62)$, and their use of the human resource frame came third $(n=47)$. On a similar note, the structural frame was the most utilized frame by the populist party members $(n=63)$, followed by the human resource frame $(n=38)$, while their use of political frame came on the third place $(n=28)$. The third research question asked whether there was any differences in the use of 
frames with specific topic (religion, politics, international affairs, social, economics). As mentioned earlier, the research included initial messages by parliament members and coded the message for its leadership frames and the most prominent topic. Two topics-politics and socialemerged as the most prominent in the parliament members messages during the six month period of the study. Of the entire sample, approximately $62.9 \%$ of the messages were politically oriented and about $19.8 \%$ focused on social issues. International affairs and economical issues generated $3.2 \%$ each. While religious issues generated $9.4 \%$ of the total topics. To answer the research question, again a frequency analysis was conducted to generate the total number of times each frame was used with the topic. The frequency analysis conducted yielded significant findings. Table 3 shows, social topics were mostly framed in terms of symbolic frame and was significantly correlated $\mathrm{r}(3)=.000, \mathrm{p}<0.001$. Political topics occurred more often in the structural frame and showed a significant correlation $\mathrm{r}(3)=.00, \mathrm{p}<0.001$. Moreover, Religious topics were often framed in terms of symbolic framing and were significantly correlated $\operatorname{r}(3)=.000, p<0.001$.

\section{DISCUSSION}

The study's first aim was to assess the differences in the use of leadership frames among Kuwaiti parliament members' political groups. To do this, 16 framing questions were empirically used to assess the most four common leadership frames discusses in the various literature. The study examined the prevalence of symbolic, structural, political, and human resource frames in parliament members and political groups Twitter messages over a period of six months. Over all, the most common frames were, in order of predominance, structural, political, symbolic, and human resource. The structural frame is usually associated with the notion of bureaucracy and power, and depends on the rationality that any problem can be solved by any group if it is organized into an appropriate structure and divided into manageable units. The coding for this variable was done in such a way that a high score meant that the MP had well organized structural leadership style. Structural leadership frame entails that the parliament member strives to accomplish established goals, coordinates and control to achieve objectives and implement strategies to fit particular circumstances.

Results showed, therefore, that among Islamist, liberal and populist party groups, structural frame was the most common used frame. The predominance of the structural frame in the three political groups' messages suggests the importance and potential influence of their messages in the social media sphere. In Kuwait, where $24 \%$ of social media content was found to be political, MPs are expected to provide their goals, objectives, strategies, and provide answers to political problems to their followers. Although political leadership frame was found the second most dominant among parliament members' messages, it was the most prevalent frame by the independent group only and the second most prevalent frame among liberal group's Twitter messages. As suggested in the literature, the political frame assumes a continuing competition, focuses on conflict and negotiation, and emphasizes individual and group interest. The independent group members don't belong to any political ideology or political parties, and rather act upon their own political agendas. Therefore, they tended to use Twitter messages as a tool to defend their views, actions and voting. Political frame was the was prominent frame among independent parliament members as they act independently and don't have the support of political parties for their actions and voting in the assembly, therefore they need to justify their positions to the public as this frame suggests that leaders advocate and negotiate their views with their followers (Comwings et al., 1996). In addition, this frame entails interest in interest groups and understanding of diversity which independent group members may use as a strategy to gain additional support from those groups (Mosser \&Walls, 2002). Since independent group members act independently in which 
they don't belong to organizations or political blocs, it is inevitable to show interest in diversity and interest groups to gain additional popularity among those groups. The study also showed that the political frame occurred as the second most common frame among the liberal group. As discusses in the literature, liberal group's main objectives include respect for human rights, social justice and interest in political developments. Therefore, the political frame was especially evident in liberal group's messages as it meets their objectives and their audiences' expectations. The study revealed that the symbolic frame was the second most commonly used frame by the Islamist group. The predominance of the symbolic frame in the Islamists group's can be explained by the Islamist group's aspiration and purpose. The symbolic frame entails that members use symbols and culture to provide a shared sense of mission and identity (Comwings et al., 1996). The questions to answer this variable were mainly about the use of religious quotes, culture, and human values and traditions. Therefore, as explained in the literature, Islamist members are concerned with social and cultural issues and this frame is based on things embedded in the culture such as Sharia law, religious values, or quotes from the Qura'an. Although the most common used frame by the populist party was the structural frame, the human resource frame ranked second. The populist party encourages labour unions and organizations and represents unions' needs in the assembly, therefore the human resource frame resembles these objectives as the frame includes being responsive to people's needs as well as people's empowerment.

In addition, the human resource frame was ranked third among the liberal group framing. As the human resource frame focuses on human needs and value feelings and relationships through facilitation and empowerment (Mosser \&Walls, 2002). The aptness for liberal members to empower their followers and encourage political participation is inevitable as they believe in building a civil society and achieve democracy. The final aim of this study was to investigate whether the prevalence of frames in MPs messages varied by topic. There has been a trend in the use of the four leadership frames-human resource, politics, structural, and the symbolic-as they were associated with the general topic of the message. In general, political issues were especially evident in the structural frame messages. This may be due to the finding that the structural frame is concerned with issues of leaders' strategies, goals and objectives. MPs strategies and goals are usually intersected with political issues such as laws, policies, corruption, the constitution and new regulations. The social frame was mostly associated with the symbolic frame which may be explained by the nature of the frame that focuses on traditions and human values. Moreover, religious issues were mostly found in the symbolic frame and that makes sense as the frame focuses on religious quotes, values and traditions which are usually issues related to religion.To conclude, parliament members in Kuwait utilize social media to interact, build their social capital and gain public acceptance using various leadership frames such as symbolic, structural, political, and human resource frame. Yet, the most dominant frame used by Kuwaiti parliament members in Twitter was the structural frame that suggests that leaders set direction, strategy, causes and effect, and hold people accountable. The way parliament members frame their messages in Twitter and the differences in leadership framing among political groups that this study prevailed can have important implications for public understanding and evaluation of political actors, political parties, and social media literacy. For further research, it is important to identify further characteristics that may be qualified for testing each frame on a political context as Bolman \& Deal's leadership frames focuses on organizational leaders.

\section{REFERENCES}


1-Alfadhly, S. (2011, February 18). Social Networks effects on national security. Alaan online. Retrieved September 7, 2011 from http://www.alaan.cc/

2-Alfuzai, M. (June 23, 2007). Are Political Parties a Must Now? Kuwait Times. Retrieved on October 23, 2011 from http://www.kuwaittimes.net/read news.php?newsid=OTAzMjk0MjIy 3-AlQassemi, S. (2011, May 31). Gulf Governments Take to Social Media. Middle East Online. Retrieved September 10, 2011 from http://middle-east-online.com/english/?id=46414

4-Al-Mazeedi, L. \& Ibrahim, I. (1998). The educational and social effects of the Internet on Kuwait University students. Paper Presented at the Conference on Information Superhighway, Safat, Kuwait.

5-AlMutairi, J. (September 22, 2011). Twitter Attracts Kuwaiti Parliament Members. AlWatan Newspaper. Retrieved on October 20, 2011 from http://alwatan.kuwait.tt/pdfhome.aspx?type $=$ Cal\&id=20/09/2011\&year=2011

6-Arab Social Media Report (2011). Dubai School of Government, 2. Retrieved September 5, 2011 from http://www.dsg.ae/portals/0/ASMR2.pdf

7-Bolman, L.G. \& Deal, T.E. (1984). Modern Approaches to Understanding and Managing Organizations. San Francisco: Jossey-Bass.

8-Bolman, L.G \& Deal, T.E. (1991). Leadership and Management Effectiveness: A Multi-frame, Multi-Sector Analysis. Human Resource Management, 30 (4):509-534.

9-Carlson, N. (April 4, 2011). Twitter Has Less Than 20 Million Active Users. Business Insider. Retrieved on October 30, 2011 from http://www.businessinsider.com/twitter-has- less- than21-million-active-users-2011-4

10-Encyclopedia of the Nations (2011). Kuwait Political Parties. Retrieved November 2, 2011 from http://www.nationsencyclopedia.com/Asia-and-Oceania/Kuwait-POLITICAL-PARTIES.html 11-Freedom in the World (2010). Erosion of Freedom Intensifies. Freedom House. Retrieved November 5, 2010 from

http://www.freedomhouse.org/template.cfm?page=22\&year=2010\&country=7855.

12-GetConnect (2011, March 8). In Kuwait, Facebook, Twitter Prove abilities Again as Youths Organize Protests. Retrieved September 6, 2011 from

http:/www.genconnect.com/trends/kuwait-facebook-twitter-protests-middle-east-oil-socialmedia/

13-Goffman, E. (1974). Frame Analysis: An Essay on the Organization of Experience. New York: Harper \& Row.

14-Haqaq, L. (2011, August 9). Social Media Megaphone Reaches to More People. Kuwait Times Online. Retrieved September 7, 2011 from http://www.kuwaittimes.net/read_news.php?newsid=OTMzMDA5MDQ1NA

15-Hofheinz, A. (2005). The Internet in the Arab World: Playground for Political Liberalization. International Politics and Society, 3, 78-96.

16-Herb, M. (2009). Kuwait Politics Database. Retrieved on October 30, 2011 from http://www2.gsu.edu/\%7Epolmfh/database/database.htm

17-Internet Usage in the Middle East (2010). Internet World Stats: Usage and Population Statistics. Retrieved March 3, 2011 from http://www.internetworldstats.com/stats5.html

18-Kareem, M. (2011). Why Did Kuwaiti Islamists Divorce the Government? The University of Chicago Divinity School Publications, Sightings. Retrieved on November 2, 2011 from http://divinity.uchicago.edu/martycenter/publications/sightings/ archive_2011/0623.shtml

19-Ku, G., Lee, L., \& Pfau, M. (2003). The Impact of Web Site Campaigning on the Traditional News Media and the Public Information Processing. Journalism and Mass Communication Quarterly, 80(3), 528--547. 20-Laggat, H. (March 12, 2010). Less Than a Quarter of Twitter Users Active. Biz Report. Retrieved on October 30, 2011 from http://www.bizreport.com/2010/03/less_than_a_quarter_of_twitter_users_active.html 
21-Mosser, N. \& Walls, R. (2002). Leadership Frames of Nursing Chairpersons and the Organizational Climate in Baccalaureate Nursing Programs. Southern Online Journal of Nursing Research, 2 (3).

22-Nielson (2011). Social Media Report. Retrieved September 12, 2011 from http:// blog.nielsen.com/nielsenwire/social/

23-Ogg, E. (September 8, 2011). We Have 100 Million Active Users. Gigaom. Retrieved on October $\quad 30,2011$ from http://gigaom.com/2011/09/08/twitter-ceo-we-have-100m-active-users/

24-U.S Department of State (2010). Background Note: Kuwait. Retrieved October 20, 2010 from http://www.state.gov/r/pa/ei/bgn/

25-WAN/IFEX (2008). Proposed Internet law aims to silence critical bloggers. Retrieved November 2, 2010 from

http://www.ifex.org/kuwait/2008/08/13/proposed_internet_law_aims_to_silence/

26-Wheeler, D. (2001). The Internet and public culture in Kuwait. Gazette, 63(2-3), 187-201.

27-Wheeler, D. (2003). The Internet and Youth Subcultures in Kuwait. Journal of ComputerMediated

Communication,

$8(2)$.

28-Wheeler, D. L. (2006). The Internet in the Middle East: Global Expectations and Local Imaginations in Kuwait. New York: State University of New York Press.

29-Roddy, M. ( June 3, 2011). Kuwaitis Protest Demand Prime Minister Resign. Reuters Africa. Retrieved September 10, 2011 from

http://af.reuters.com/article/egyptNewsidAFLAE36903720110603?pageNumber=2\&virtualBrand Channel $=0$

30-Sasnett, B. \& Ross, T. (2007). Leadership Frames and perceptions of Effectiveness Among Health Information Management Program Directors. Perspectives in Health Information Management, 4.

31-Semetko, H.A. \& Valkenburg, P.M. (2000). Framing European Politics: A content Analysis of Press and Television News. Journal of Communication, 93-108.

32-Shebeb, D. (2011, June 9). Kuwaiti Deputy Prime Minister Sheikh Ahmed Al Fahad Resigns, Al Arabiya Reports. Al Arabiya News Online. Retrieved September 5, 2011 from http://www.alarabiya.net/articles/2011/06/09/152554.html

33-The Estimate (1999). Kuwait's Political System: Parliament. Political and Security Intelligence Analysis of the Islamic World and its Neighbors, XI, 13.

34-Zolner, J. (2010). The Four Frames: An Idea That Sticks. Harvard School of Education Alumni Bulletin, 1. Retrieved September 15, 2001 from

http://www.gse.harvard.edu/ppe/enews/ hihe/10hihe1/frames.html

35-Ziegler, H. (2011). The Political System of Kuwait. Helen Ziegler and Associates. Retrieved on November 12, 2011 from

http://www.hziegler.com/locations/middle-east/kuwait/articles/political-system-of-kuwait.html 
The Turkish Online Journal of Design, Art and Communication - TOJDAC April 2012 Volume 2 Issue 2

Appendix A

TABLE 1

Frequency of Twitter Messages Among Sample for the Period of Analysis*

\begin{tabular}{|c|c|c|c|}
\hline Parliament Member Name & Political Group & $\begin{array}{c}\text { Total Number of Tweets for the } \\
\text { Total Period }\end{array}$ & $\begin{array}{c}\text { Total Number of Analyzed Tweets } \\
(25 \% \text { of population) }\end{array}$ \\
\hline Dr. Aseel Alawadhi & Liberal & 212 & 33 \\
\hline Saleh Almulla & Liberal & 128 & 61 \\
\hline Dr.Waleed Altabtabie & Islamist & 244 & 43 \\
\hline Dr.Faisal Almuslim & Islamist & 172 & 22 \\
\hline Ahmed Alsadoun & Populist Party & 188 & 11 \\
\hline Ali Aldaghbasy & Populist Party & 48 & 11 \\
\hline Marzough Alghanim & Independent & 44 & \\
\hline Shaieb Almwezry & Independent & 44 & \\
\hline
\end{tabular}

TABLE 2

\begin{tabular}{|c|c|c|c|c|}
\hline \multicolumn{2}{|c|}{ Frequency of Frames (Ranks) Among Parliament Members' Political Groups } \\
\hline & Symbolic Frame & Structural Frame & Political Frame & Human Resource Frame \\
\hline Islamist Group & $65(2)$ & $88(1)$ & $60(3)$ & $19(4)$ \\
\hline Independent Group & $5(3)$ & $16(2)$ & $18(1)$ & $3(4)$ \\
\hline Liberal Group & $34(4)$ & $68(1)$ & $62(2)$ & $47(3)$ \\
\hline Populist Party & $21(4)$ & $63(1)$ & $28(3)$ & $38(2)$ \\
\hline Total & $125(3)$ & $235(1)$ & $168(2)$ & $107(4)$ \\
\hline
\end{tabular}

TABLE 3

\begin{tabular}{|c|c|c|c|c|c|}
\hline \multicolumn{7}{|c|}{ Issue-Frame Relationship (in numbers) } \\
\hline Issues & Symbolic Frame & Structural Frame & Political Frame & $\begin{array}{c}\text { Human Resource } \\
\text { Frame }\end{array}$ & Total \\
\hline Social & $58(52)^{* *}$ & $17(15.3)^{* *}$ & $8(7.2)^{* *}$ & $28(25.2)^{*}$ & $111(100)$ \\
\hline Politics & $14(3.4)^{* *}$ & $196(47.8)^{* *}$ & $139(33.9)^{* *}$ & $61(14.8)$ & $410(100)$ \\
\hline Religion & $45(54.2)^{* *}$ & $1(1.2)^{* *}$ & $1(1.2)^{* *}$ & $36(43.3)$ & $83(100)$ \\
\hline International Affairs & $1(6.2)$ & $4(25)$ & $8(50)$ & $3(18.7)$ & $16(100)$ \\
\hline Economics & $7(12.2)$ & $17(29.8)$ & $12(21)$ & $21(36.8)$ & $57(100)$ \\
\end{tabular}

Notes: Values in parentheses represent percentages.

Values with * were significant at least at $\mathrm{p}<.05$. 